УДК 37.017

DOI: $10.17223 / 1998863 \mathrm{X} / 42 / 13$

\title{
Е.И. Кириленко
}

\section{АНТИЧНЫЙ АГОН И ОПЫТ СОПЕРНИЧЕСТВА}

\begin{abstract}
С опорой на идеи Ничще предпринят анализ противоречивой природы античного агона, не только стимулирующего творчество, но и несущего потенииал «ревности, вражды, зависти». Рассматривается ситуация соперничества в свете теории ресентимента М. Шелера. Обозначена актуальность исследования феномена жестокости как изнанки соперничества.

Ключевые слова: античная культура, греческое состязание, агон, Ф. Ницие, ресентимент, М. Шелер, жестокость, междисииплинарный анализ.
\end{abstract}

Изучение античного опыта - это путь постижения опыта современной культуры, развитие которой исполнено бесконечными античными реминисценциями. «История того, что мы можем назвать культурой в нашем современном смысле, начинается... в греческой среде» [1. С. 13].

Античная практика «заботы о себе» открывает возможность исследовать идею агона, соревновательной природы позиции античного человека, его способа существования. «Идея состязания как важнейшего элемента общественной жизни издавна неотделима от нашего представления о культуре Эллады» [2. С. 79]. Спор - содержание философских диалогов, античных антистерий, личных стратегий (вспомним Герострата).

Греческое состязание - это «состязание в мудрости, мужестве, богатстве, красноречии» [3]. Античное воспитание было насквозь пропитано идеей агонистики. Приобщение к мудрости - в педагогике Сократа - это путь диалектики. Пример агона как жизненного принципа можно увидеть в практике остракизма, первоначальный смысл которого заключался в том, что никто не должен был «быть наилучшим», так как «благодаря этому иссякает соревнование, и вечное жизненное основание эллинского государства было бы в опасности» [4].

Состязание как принцип общественной жизни требовало определенного порядка. В греческом концепте «заботы о себе», реконструированном Фуко и прокомментированном В.Л. Лехциером [5], и платоновская и эллинистическая фаза «культуры себя», утверждая или элиминируя также принцип «заботы о других», сохраняет в качестве важнейшей практику внутренней работы, внутреннего соревнования с «врагом», который находится в самом себе. Имеется в виду борьба со своими страстями, овладение собственными желаниями. В каком направлении могла идти внутренняя работа, каковы могли быть возникающие ограничения, можно выявить, обращаясь к анализу идеи «гомеровского соревнования» у Ф. Ницше.

Как отмечает Ф. Зелинский, Ницше был «сыном и проповедником античности, от первой до последней написанной им строки» [6]. Опыт погружения в Античность сказался как в отношении стиля, усвоенного от Саллюстия и Горация, стиля сжатого, сурового, «яркого и твердого как сталь», так и 
в отношении позиции борьбы с этической традицией и открытия новых этических горизонтов.

Тема агона у Ницше - это прежде всего тема этическая. Принцип соревнования у него необходимо связан с философией воспитания сверхчеловека, «великого человека» - того, «что нам вечно будет дорого и мило, чего никакие позднейшие познания не могут нас лишить» [7].

Ф. Зелинский указывает на то, что идею воли к власти Ницше заимствовал из философии стоиков. На труды, например, Панэтия Родосского (стоик, жил в Риме с 146 по 131 г.) ссылается Цицерон в трактате «Об обязанностях», где «воля к власти» (appetitio principatus) названа в качестве одного из четырех стремлений, изначально присутствующих в душе человека. Цицерон пишет о «стремлении главенствовать», из которого «возникают величие духа и презрение к делам человеческим» [8].

Но путь к политической практике, управлению полисом открывала победа в соревновании. Античная система аристократического воспитания предполагала работу над собой (mathesis и askesis - самопознание и «преобразование себя») [5], включая физическую закалку и агонистику. Состязание несло наслаждение само по себе. Но вместе с тем оно производило отбор лучших. «Аристократия бывает либо трудовой, либо паразитической; в последнем случае она будет болезнетворным ферментом в государстве», в первом же случае ее жизнь будет исполнена «трудов и лишений; но за все вознаграждала, при здоровом направлении воспитания, победа и власть» [6]. Ницше обращает внимание на специфику этического фона ситуации агона. В эмоциональной палитре соревнования - «ревность, вражда, зависть». «В душной атмосфере борьба является счастьем, спасением, а жестокость победы - вершиной ликования жизни» [4].

Борьба была окрашена страстями, которые, как отмечает Ницше, современность не всегда способна оценить адекватно. Будучи порочными для современного человека, вражда и зависть воспринимались греком как доблесть. При этом, показывает философ, противоборство как бы освящено образами двух Эрид, которые символизируют два комплекса страстей, переполняющих души агонистов. Притом что Эрида в древнегреческой мифологии - богиня ссоры, раздора, хаоса, возможно на этом фоне выделение двух оттенков, различающих разные степени враждебности.

Эрида, рожденная черной ночью, побуждает к войне. Она зла и жестока, и «никто из смертных не может выносить ее». Вторая Эрида, пребывающая среди людей, достойна похвалы. Она, порождая соперничество, побуждает к труду, творчеству, она поставлена «на корни земли». И пробуждая «злобу и зависть», она порождает стремление действовать. Завистливы и боги, но и душа человека «пылает завистью к каждому другому живому существу», побуждая к благодетельному труду [4].

Два важных урока следуют из ницшеанского анализа античного агона. Агон изобилует страстными состояниями. Здесь и злоба, и зависть, и раздор, и вражда. Агон чреват жестокостью. Природные импульсы определяют поведение архаического грека. Жестокость здесь естественна и органична так же, как органична жестокость в природе.

Кроме того, состязание несет в себе разные возможности развития. Есть раннее утро греческого агона. Слова Ницше о гомеровском агоне - это 
«песнь о силе и радости, о соревновании и воле к первенству и власти» [6]. Но ситуация соперничества может развиваться, модифицироваться, определенным образом инфицироваться - подобно тому, как дорическая Греция это утро, за которым рассвет классики неизбежно сменится ее закатом. Классика принесет зрелые плоды, но в ней присутствует начало истощения. Об этом писал В. Йегер: «Ослабление метафизической глубины и серьезности в культурном опыте, оскудение ценностной составляющей, выхолощенной индивидуализмом» [1. С. 390] привели к культурному закату [Там же. С. 388], хотя «уровень интеллектуального и эстетического воспитания был наивысшим»: обнаруживались «интеллектуальное пламенение к красоте и ненасытная жажда раскованной игры умственных сил» [Там же. С. 390]. Образы двух Эрид могут быть поняты в ключе изменения природы самого соревнования: соперничество может быть радостным и творческим, но возобладание болезненной и ночной Эриды может привести к абсолютному излиянию ненависти, взаимному и кровавому растерзанию.

Опыт анализа страстных, темных душевных состояний, предложенных Ницше на материале античного агона, наследовал М. Шелер в своей работе о ресентименте [9]. Вынеся за скобки ницшеанскую идею связи ресентимента с христианской этикой, Шелер обратил внимание на саму природу ресентимента как сложного комплекса негативных переживаний, где выявляется «блуждающая во тьме души затаенная и независимая от активности “Я” злоба, которая образуется в результате воспроизведения в себе интенций ненависти или иных враждебных эмоций и, не заключая в себе никаких конкретных враждебных намерений, питает своей кровью все возможные намерения такого рода» [9].

Предпринимая феноменологический анализ опыта, Шелер исследует ценностные содержания сознания. Ресентимент, показывает философ, - это сильное, реактивное по своему происхождению переживание, которое носит отложенный характер и имеет отрицательную ценностную окрашенность. Это «самоотравление души», тотально негативное по своему содержанию внутреннее состояние.

Здесь существенны три важных признака. Это интенсивное переживание, пережитое и воспроизводимое вновь чувство, которое способно стать центром всей внутренней жизни личности. Это отложенное переживание естественных душевных состояний - злобы, ненависти, это месть, ждущая своего места и часа. Это искусственным образом задержанная душевная реакция. Но отложенные переживания, заключенные в бессознательное, тем более готовы произвести агрессивный выброс. И самое важное: ресентимент возникает из чувства бессилия, физической или духовной слабости. Именно это заставляет человека сдерживать негативные эмоции.

В ситуации соперничества в палитре ресентиментных переживаний важна зависть. Зависть определяется как реакция на бессилие обрести нечто, чем обладает другой. Это другое можно «заработать, купить, отнять силой» [9], но если это невозможно - рождается болезненная реакция. Самая безнадежная ситуация возникает в случае «экзистенциальной зависти»: «Я не такой как ты, поэтому ты не имеешь права на существование». Ресентимент здесь это уязвленность, переносящая собственные неудачи на другого, усматривающая в нем причину собственной несостоятельности и рождающая желание 
упразднить эту причину. Причиной неудачи отношений становится сам факт отношений.

В современном мире, показывает Шелер, ресентимент приобретает особое качество. Если в сословном обществе человек сравнивал себя с другим внутри своего социального круга, то в современном мире сравнение и возникающее соперничество приобретают вселенский характер, поскольку утверждается желание «быть и значить больше через сравнение со всеми другими». Шелер говорит об обществе, основанном на «системе конкуренции» [9]. Глобальное соперничество становится постоянным фоном существования. Оно напоминает о себе даже там, где нет ситуации непосредственного взаимодействия.

Природа теневых аспектов соперничества, его изъязвленных проявлений его неукорененность в бытии, ценностно выстроенном универсуме. «Благородному человеку ценности даны в переживании до сравнения; подлый переживает их впервые лишь в сравнении и через его посредство» [9]. При этом человек, не включенный в ценностную партитуру жизни, имеет либо сильную позицию - и тогда он успешный актор социального действия с сомнительной системой ценностных координат. Либо он находится в слабой позиции - и тогда возникает ресентиментное сознание. Оно сложно по своей структуре: ценности еще просвечивают под покрывалом собственных желаний, и это сложное напластование погружает человека в ситуацию «ценностной иллюзии».

Примеры ресентиментной позиции Шелер видит в межпоколенном конфликте, феномене религиозного отступничества, внутрисемейных родственных противостояниях.

Интересно рассуждение философа об интеллектуальном ресентименте. Позиция отрицания и критики несет в себе «яд ресентимента». Ресентиментная критика - в отличие от критики «подлинной и плодотворной» - живет отраженными содержаниями. Здесь критический взгляд на мир сопровождается не открытием очевидностей, а критикой мнений, рождающих некие «псевдопозитивности», за которыми скрываются «отрицания и девальвации» [9]. Яд ресентимента заключен в этой внутренней слабости, недостаточности мужественного взгляда в отношении самой реальности.

Один из итоговых выводов Шелера: ресентимент - «источник переворотов в извечном порядке человеческого сознания, одна из причин заблуждений в познании этого порядка и претворении его в жизнь» [9]. Потерпевший неудачу в отношении с миром, потерявший систему жизненных координат, внутренне скованный, несвободный, теряющий почву под ногами современный человек способен к неконтролируемому выбросу негативных эмоций, разрядке в виде злобы, отвращения, жестокости, «беспредметной брани», насилия. Ресентимент как патология ценностной сферы, как нравственная болезнь способен приобрести характер эпидемии.

Рассуждения Шелера о болезненных проявлениях взаимодействия в обществе, основанном на «системе конкуренции», актуальны для исследования ситуации роста насилия, агрессии в современном мире (см.: [10]).

Особого внимания заслуживает феномен жестокости. Жестокость в самом общем плане понимается как «особое, специфическое проявление человеческой агрессии» [11]. Отчетливо проступающая в современном культурном пространстве, она становится проблемой для философов, социологов, криминологов. 
В философско-гносеологической перспективе феномен жестокости поразному открывается в рамках классической и неклассической парадигм. В классике мир в основе своей мыслится разумным, и жестокостью можно овладеть с помощью рационально выстроенных усилий [12]. В неклассике жестокость иррациональна и не поддается рациональному контролю.

Следует отметить, что обращение к исследованию феномена жестокости в отечественной литературе было инициировано, прежде всего, психиатрами и криминологами [13]. В работе Л.М. Балабановой выделена специальная глава, посвященная жестокости [14].

Правовой дискурс оценивает жестокость как деструкцию, фактор противоправного поведения. Жестокость обозначает «особо брутальные (грубые) способы совершения преступления», определенные свойства характера преступника, а также комплекс объективных и субъективных факторов преступления, «включая его последствия для общества в целом» [Там же]. Правовой дискурс несет в себе ясность, систематичность прагматизм. Выделяется жестокость, санкционированная обществом, законопослушная (функциональная) - забои скота, уничтожение бездомных животных, исполнение высшей меры наказания [Там же].

Предлагается классификация видов жестокости: преднамеренная и непроизвольная, сознательная и неосознанная, физическая и психическая жестокость, жестокость как действие и бездействие, детская, ритуальная, жестокость, связанная с познавательным мотивом, жестокость как личностная черта (преднамеренное причинение страданий и мучений) и жестокость, санкционированная обществом.

Проблемой для криминолога является констатация факта: жестокость не только и не столько факт душевной патологии. Она акт свободного выбора. «Жестокость нельзя списать на патологию психики. С помощью специально разработанной программы было изучено пятьсот уголовных дел об убийствах, совершенных с особой жестокостью... более половины верифицированных психиатрами убийств с особой жестокостью совершили психически здоровые люди» [Там же].

Для социального психолога жестокость предстает как феномен девиации, отклонения от нормы, предполагающий действие несанкционированными средствами. Жестокость рассматривается как социально-психологический феномен, ориентированный на причинение «страданий другому существу неприемлемым в данной культуре способом» [15].

В этическом аспекте жестокость - сложное образование, статус которого определен пересечением различных этических систем. В иерархизированной (шелеровской) системе координат это антиценность. В религиозно-философской традиции жестокость открывается как аспект зла, обретающий все более негативную определенность, наполняемость, окрашенность в движении от Люцифера к Ариману [16]. Культура сопротивляется легализации жестокости, изгоняет ее. У французского философа Андре Конт-Спонвиля жестокость определяется как «стремление причинять другим страдание, получая при этом удовольствие... Жестокость один из самых тяжких грехов, хуже которого нет и быть не может» [17. С. 186]. Жестокость деструктивна. У Г.Р. Черновой понятие «жестокость» связано с близкими по смыслу понятиями «насилие», «агрессия», 
«враждебность», «отчуждение», «овеществление», «бесчеловечность» (антигуманность) [11].

В логике рядоположенности этических ценностей (у Макса Вебера, утверждающего «политеизм ценностей», этический плюрализм, конфликт ценностей (см.: [18])) жестокость парадоксальным образом дрейфует к архипелагу культурно освоенных территорий. В самом деле, можно обратиться к определению ценности в логическом дискурсе: ценность - «предмет некоторого интереса, желания, стремления и т.п., или... объект, значимый для человека или группы лиц» [19]. Если жестокость - «особое, специфическое проявление человеческой агрессии» [10], связанное с причинением страдания другому живому существу или нежеланием помочь преодолеть страдания и испытывающему от этого удовлетворение (см.: [20]), значит есть люди или группа людей, для которых жестокость - «предмет некоторого интереса, желания, стремления». Нужно признать, что сама попытка научного исследования феномена жестокости есть способ ее легитимации как чего-то значимого.

Наконец, в условиях ценностного релятивизма, когда укрепляется позиция «почему бы и нет», акцентуация темы жестокости - признак потери этических координат, «ценностной растерянности» (С. Вшолек).

Тема состязательности, как показал М. Шелер, сохраняет безусловное значение для современной культуры, приобретая - на фоне множественности и мозаичности современного мира - характер универсального жизненного постулата. Анализ этой темы выполняет важные педагогические задачи: как выработать стиль жизни в условиях конкуренции, борьбы, соперничества, научиться жить достойно, утверждая себя, но при этом не превращая соперничество в ситуацию конфликта, противостояния, противоборства, войны.

Проявления агрессивности, жестокости не самодостаточны. Как отмечают антрополог М. Бутовская, неконтролируемая агрессия несет угрозу сплоченности группы и ее видовому выживанию. Кроме того, просто сила и агрессивность не могут быть единственным основанием власти, не являются главным критерием, определяющим социальный статус. А спонтанное убийство, так или иначе, наказывается. В ходе эволюции совершенствовались механизмы, сдерживающие неуправляемую агрессию - от ритуалов явной или магической мести до уголовного кодекса. У высших животных кроме форм агрессии отмечены и описаны «ритуалы примирения» [10].

Опыт исследования культурной динамики также обнаруживает некую сохраняющую историческую жизнь ритмику: бездну ненависти демонстрирует архаика, но опыт высшей религиозной жизни сохраняет свое - иногда подводное, на уровне культурных архетипов - музыкальное звучание. У Ницше борьба с христианством сопровождалась попыткой написать новое Евангелие [6]. В этическом плане спасительны высшие ценности. Шелер приводит слова Гете: «Против превосходства другого нет иного спасительного средства, кроме любви» [9]. В современном мозаичном мире ведутся поиски формирования нового этоса: «Позволить другим идти своим путем удивительно непросто. Этот подход, выражаясь словами Кукатаса, иногда требует «терпеть нетерпимое», и в нем так много от безразличия, что его сложно было бы оправдать, если бы терпение было самоцелью. Однако терпение - необходимая, хотя и не самая приятная, часть искусства мира, добрососедства и любви, и именно это делает его столь ценным» [21]. 


\section{Лuтература}

1. Йегер В. Пайдейя. Воспитание античного грека. Т. 1 / пер. с нем. А.И. Любжина. М. : Греко-латинский кабинет® Ю.А. Шичалина, 2001. 393 с. [Электронный ресурс]. URL: http://www.portal-slovo.ru/philology/37460.php (дата обращения: 05.11.2017).

2. Хёйзинга Й. Homo Ludens : Статьи по истории культуры / пер. Д.В. Сильвестрова; коммент. Д.Э. Харитоновича. М. : Прогресс-Традиция, 1997. 416 с.

3. Козьякова М.И. История. Культура. Повседневность. Западная Европа: от античности до XX века. М. : Весь мир. 2002. 360 с. [Электронный pecypc]. URL: https://www.booksite.ru/localtxt/koz/yak/ova/his/tory/index.htm (дата обращения: 05.11.2017).

4. Ницие Ф. Гомеровское соревнование [Электронный ресурc]. URL: http://www.nietzsche.ru/ works/other/gomer-competitionНТцше (дата обращения: 05.11.2017).

5. Лехииер В.Л. «Забота о себе» и проблема философского образования [Электронный реcypc]. URL: http:/hpsy.ru/public/x4111.htm (дата обращения: 05.11.2017).

6. Зелинский Ф.Ф. Ф. Ницше и античность [Электронный ресурс]. URL: http://www.nietzsche.ru/look/century/antichnost/ (дата обращения: 05.11.2017).

7. Нищше Ф. Философия в трагическую эпоху Греции [Электронный ресурс]. URL: http://www.nietzsche.ru/works/other/philosof/ (дата обращения: 05.11.2017).

8. Марк Туллий Цицерон. О старости. О дружбе. Об обязанностях / пер. с лат. и коммент. В.О. Горенштейна. М. : Наука, 1993 (репринт текста издания 1974 г.) // [Электронный ресурс]. URL: http://ancientrome.ru/antlitr/t.htm?a=1423775001 (дата обращения: 05.11.2017).

9. Шелер M. Ресентимент в структуре моралей // [Электронный ресурс]. URL: http:/jour.isras.ru/index.php/socjour/article/view/402/377 (дата обращения: 05.11.2017 г.)

10. Бутовская М.Л. Агрессия и примирение как проявление социальности у приматов и человека [Электронный ресурс]. URL: http://staff.ttu.ee/ bgordon/oppetegevus/valjendus/ref_rus/orig_article_6.pdf (дата обращения: 05.11.2017 г.)

11. Чернова Г.Р. Феномен жестокости: Культурно-антропологический аспект: автореф. дис. ... канд. филос. наук. СПб., 2001 [Электронный pecypc]. URL: http://www.dissercat.com/content/fenomen-zhestokosti-kulturno-antropologicheskii-aspekt (дата обращения: 05.11.2017).

12. Честертон Г.К. Эссе. В защиту детективной литературы [Электронный ресурс]. URL: http://www.chesterton.ru/essays/0042.html (дата обращения 05.11.2017).

13. Барковская А.П. К проблеме философского понимания жестокости [Электронный реcypc]. URL: https://www.fundamental-research.ru/ru/article/view?id=37184 (дата обращения: 05.11.2017).

14. Балабанова Л.М. Судебная патопсихология (вопросы определения нормы и отклонений). Донецк : Сталкер, 1998. 432 с. [Электронный pecypc]. URL: http://svitk.ru/004_book book/13b/2813 balabanova-sudebnaya patopsihologiya.php (дата обращения: 05.11.2017).

15. Абдулаев Ш.М., Абдулаева Д.С. Жестокость как психосоциальный феномен // Психология XXI века: сб. материалов V Междунар. науч.-практ. конф. молодых ученых. СПб., 2009. T. 1. C. 14-19.

16. Иванов Вяч. Пролегомены о демонах. Лик и личины России [Электронный ресурс]. URL: http://rvb.ru/ivanov/1_critical/1_brussels/vol3/01text/02papers/3_139.htm (дата обращения: 05.11.2017).

17. Конт-Спонвиль А. Философский словарь / пер. с фр. Е.В. Головиной. М. : Этерна, 2012. $752 \mathrm{c}$.

18. Троиикий К.Е. Переоценка ценностей в аксиологической мысли М. Вебера [Электронный ресурс]. URL: https://iphras.ru/uplfile/ethics/biblio/troitskiy/troitskiy.revaluatio.pdf (дата обращения: 05.11.2017).

19. Ивин A.A. Основы теории аргументации [Электронный pecypc]. URL: http://www.rulit.me/books/osnovy-teorii-argumentacii-uchebnik-read-380178-1.html (дата обращения: 05.11.2017).

20. Жестокость // Еврейская энциклопедия Брокгауза и Ефрона [Электронный ресурс]. URL: https://ru.wikisource.org/wiki/ЕЭБЕ/Жестокость (дата обращения 05.11.2017г.)

21. Новиков B. Предисловие // Кукатос Ч. Либеральный архипелаг. Теория разнообразия и свободы / пер. с англ. Н. Эдельмана под науч. ред. А. В. Куряева. М., 2011. 482 с. [Электронный pecypc]. URL: http://www.liberal.ru/upload/files/Kukatas_Arhipelag_p001-045.pdf (дата обращения: 05.11.2017). 
Elena I. Kirilenko, West Siberian Branch of Russian State University of Justice (Tomsk, Russian Federation).

E-mail: e.kirilenko@ngs.ru

Vestnik Tomskogo gosudarstvennogo universiteta. Filosofiya. Sotsiologiya. Politologiya-Tomsk State University Journal of Philosophy, Sociology and Political Science. 2018. 42. pp. 127-135.

DOI: $10.17223 / 1998863 X / 42 / 13$

THE ANCIENT GREEK AGON AND THE EXPERIENCE OF RIVALRY

Keywords: antique culture, Greek rivalry, agon, F. Nietzsche, ressentiment, M. Scheler, cruelty, interdisciplinary analysis.

The idea of "taking care of the self" and the ancient Greek agon are closely related. The situation of rivalry needs to be rationed. But the formation of "self-culture" also contains an agonizing element of competition with oneself. Friedrich Nietzsche's position and his analysis of Homeric competition are important to understand the nature of the ancient Greek agon. The ancient system of aristocratic education included physical training and agonism. The best person was selected by a competition. Greeks understood enmity and envy, which were usual in a competition, as valor. A person can get two important lessons from Nietzsche's analysis. Agon abounds in passionate states. In addition, competition includes different development possibilities: rivalry can be joyful and creative, but also can degenerate into a mutual and bloody torment. The analysis of the passionate, dark soul states proposed by Nietzsche on the material of ancient agonism was inherited by Max Scheler. Ignoring Nietzsche's idea of the connection of ressentiment with Christian ethics, Scheler paid attention to the very nature of ressentiment as a complex set of negative experiences. There are three important features here. Firstly, it is intense experience that can become the center of all the inner life of the individual. Secondly, it is deferred experience, revenge that waits for its place and hour. Thirdly and most importantly, it is ressentiment arising from the feeling of impotence, physical or spiritual weakness that makes a person restrain negative emotions. The nature of the shadow aspects of rivalry and its manifestations is unrootedness in being and the value-built universe. Ressentiment as a pathology of the value sphere and a moral disease is able to acquire the character of an epidemic. Scheler's ideas about the painful manifestations of interaction in a society based on a "competition system" are relevant for studying the situation of the growing violence and aggression in the modern world. Special attention should be paid to the phenomenon of cruelty as a specific manifestation of human aggression. Clearly visible in the modern cultural space, it becomes a problem for philosophers, sociologists, criminologists. One of the most important questions of modern culture is how to develop a lifestyle in a competitive environment, how to learn to live with dignity without turning rivalry into a situation of conflict, confrontation, war. Manifestations of aggressiveness and cruelty are not self-sufficient. The study of cultural dynamics shows a certain rhythm that preserves the historical life: the archaic demonstrates the abyss of hatred, but the experience of the higher religious life on the cultural level of archetypes retains its own "musical" sounds. In the ethical sense, the highest values are salvific. Scheler cites Goethe's words: "Against the great superiority of another there is no remedy but love."

\section{References}

1. Jaeger, W. (2001) Paydeyya. Vospitanie antichnogo greka [Paideia. Education of the Ancient Greek]. Translated from German by A. Lyubzhin. Vol. 1. Moscow: Greko-latinskiy cabinet Yu.A. Shichalina. [Online] Available from: http://www.portal-slovo.ru/philology/37460.php. (Accessed: 5th November 2017).

2. Huizinga, J. (1997) Homo Ludens; Stat'i po istorii kul'tury [Homo Ludens; Articles on the History of Culture]. Translated by D.V. Silvestrov. Moscow: Progress-Traditsiya.

3. Kozyakova, M.I. (2002) Istoriya. Kul'tura. Povsednevnost'. Zapadnaya Evropa: ot antichnosti do XX veka [History. Culture. Everyday life. Western Europe: from antiquity to the twentieth century]. Moscow: Ves' mir. [Online] Available from: https://www.book-site.ru/localtxt/koz/yak/ova/his/tory/ index.htm. (Accessed: 5 th November 2017).

4. Nietzsche, F. (n.d.) Gomerovskoe sorevnovanie [Homeric competition]. Translated from German. [Online] Available from: http://www.nietzsche.ru/ works/other/gomer-competitionNTtsshe. (Accessed: 5th November 2017).

5. Lekhtsiier, V.L. (n.d.) "Zabota o sebe" i problema filosofskogo obrazovaniya ["Care for yourself" and the problem of philosophical education]. [Online] Available from: http://hpsy.ru/public/x4111.htm. (Accessed: 5th November 2017). 
6. Zelinskiy, F.F. (n.d.) F. Nitsshe $i$ antichnost' [F. Nietzsche and Antiquity]. [Online] Available from: http://www.nietzsche.ru/look/century/antichnost/ (Accessed: 5th November 2017).

7. Nietzsche, F. (n.d.) Filosofiya $v$ tragicheskuyu epokhu Gretsii [Philosophy in the tragic era of Greece]. Translated from German. [Online] Available from: http://www.nietzsche.ru/works/other/philosof/. (Accessed: 5th November 2017).

8. Mark Tullius Cicero. (1993) O starosti. O druzhbe. Ob obyazannostyakh [About old age. About friendship. About duties]. Translated from Latin by V.O. Gorenstein. Moscow: Nauka. [Online] Available from: http://ancientrome.ru/antlitr/t.htm?a=1423775001. (Accessed: 5th November 2017).

9. Sheler, M. (n.d.) Resentiment $v$ strukture moraley [The sentiment in the morals structure]. [Online] Available from: http://jour.isras.ru/index.php/socjour/article/view/402/377. (Accessed: 5th November 2017).

10. Butovskaya, M.L. (n.d.) Agressiya i primirenie kak proyavlenie sotsial'nosti u primatov $i$ cheloveka [Aggression and reconciliation as a manifestation of sociality in primates and humans]. [Online] Available from: http://staff.ttu.ee/ bgordon/oppetegevus/valjen-dus/ref_rus/orig_article_6.pdf. (Accessed: 5th November 2017).

11. Chernova, G.R. (2001) Fenomen zhestokosti: Kul'turno-antropologicheskiy aspect [The phenomenon of cruelty: The cultural and anthropological aspect]. Abstract of Philosophy Cand. Diss. St. Petersburg. [Online] Available from: http://www.dis-sercat.com/content/fenomen-zhestokostikulturno-antropologicheskii-aspekt. (Accessed: 5th November 2017).

12. Chesterton, G.K. (n.d) Esse. V zashchitu detektivnoy literatury [Essays. In defense of detective literature]. [Online] Available from: http://www.chesterton.ru/essays/0042.html. (Accessed: 5th November 2017).

13. Barkovskaya, A.P. (n.d) K probleme filosofskogo ponimaniya zhestokosti [To the problem of philosophical understanding of cruelty]. [Online] Available from: https:/www.fundamentalresearch.ru/ru/article/view?id=37184. (Accessed: 5th November 2017).

14. Balabanova, L.M. (1998) Sudebnaya patopsikhologiya (voprosy opredeleniya normy $i$ otkloneniy) [Judicial pathopsychology (questions of definition of norms and deviations)]. Donetsk: Stalker. [Online] Available from: http://svitk.ru/004_book_ book/13b/2813_balabanovasudebnaya_patopsihologiya.php. (Accessed: 5th November 2017).

15. Abdulaev, Sh.M. \& Abdulaeva, D.S. (2009) Zhestokost' kak psikhosotsial'nyy fenomen [Cruelty as a Psychosocial Phenomenon]. In: Psikhologiya XXI veka [Psychology of the 21st Century]. Vol. 1. St. Petersburg: A.S. Pushkin Leningrad State University. pp. 14-19.

16. Ivanov, Vyach. (n.d.) Prolegomeny o demonakh. Lik i lichiny Rossii [Prolegomena about demons. The face and masks of Russia]. [Online] Available from: http://rvb.ru/ivanov/1_critical/1_brussels/vol3/01text/02papers/3_139.htm. (Accessed: 5th November 2017).

17. Kont-Sponville, A. (2012) Filosofskiy slovar' [Philosophical Dictionary]. Translated from French by E.V. Golovina. Moscow: Eterna.

18. Troitskiy, K.E. (n.d.) Pereotsenka tsennostey $v$ aksiologicheskoy mysli M. Vebera [Revaluation of values in M. Weber's axiological thought]. [Online] Available from: https://iphras.ru/uplfile/ethics/biblio/troitskiy/troitskiy.revaluatio.pdf. (Accessed: 5th November 2017).

19. Ivin, A.A. (n.d.) Osnovy teorii argumentatsii [Fundamentals of the theory of argumentation]. [Online] Available from: http://www.rulit.me/books/osnovy-teorii-argumentacii-uchebnik-read380178-1.html. (Accessed: 5th November 2017).

20. The Society of Scientific and Jewish Publications. (n.d.) Evreyskaya entsiklopediya Brokgauza $i$ Efrona [Jewish Encyclopedia by Brockhaus and Efron]. [Online] Available from: https://ru.wikisource.org/wiki/EEBE/Zhestokost'. (Accessed: 5th November 2017).

21. Novikov, V. (2011) Predislovie [Preface]. In: Kukatos, Ch. (n.d.) Liberal'nyy arkhipelag. Teoriya raznoobraziya $i$ svobody [Liberal archipelago. The theory of diversity and freedom]. Translated from English by N. Edelman. Moscow: Mysl'. [Online] Available from: http://www.liberal.ru/upload/files/Kukatas_Arhipelag_p001-045.pdf. (Accessed: 5th November 2017). 